\title{
The Impact of Watching Captioned TV Series on Vocabulary Development of EFL Students
}

\author{
Karim Shabani \\ Allameh Mohaddes Nouri University, Nour, Iran \\ E-mail: shabanikarim@gmail.com \\ Marjan Pasha Zanussi \\ Allameh Mohaddes Nouri University, Nour, Iran \\ E-mail: Lida.Pasha.Zanussi@gmail.com
}

Received: August 30, 2015 Accepted: September 15, 2015 Published: September 15, 2015

doi:10.5296/jsel.v3i1.8301 URL: http://dx.doi.org/10.5296/jsel.v3i1.8301

\begin{abstract}
Second language development could be achieved through various teaching and learning processes; however, applying multimedia technology has facilitated this process. This study aimed at examining the effect of captioned TV series on developing vocabulary knowledge of EFL students. There were forty intermediate male students learning English in Shokouh institute of Nowshahr, Mazandaran, Iran. The classes were held two sessions a week. The participants were randomly selected into control and experimental groups. Before the experiment, a 20-item vocabulary matching test was conducted as the pre-test. The vocabularies including in this test were chosen from a TV series in order to investigate their knowledge of vocabulary. After the pre-test 'Friends', An American TV series, was shown to both groups. English captioned episode was shown to the experimental group and non-captioned episode to the control one. After that, a post-test was conducted to examine the development in each group. Both independent and paired t-tests were carried out. The results of this study revealed that the participants in experimental outperformed those in control group in terms of their vocabulary development. The findings may be shared with other teachers in order to inform how captions affect the vocabulary learning of Iranian EFL students.
\end{abstract}

Keywords: Captioned TV series, captions, vocabulary learning 


\section{Introduction}

Language teaching and learning are human activities; they are social just as much as they are linguistic entities. Language teaching reflects the times it takes place in. There has always been increasing stress on English language teaching as a mechanism for communication and technology has played a very special role in facilitating the authentic communication. Part of the professional role of teachers is to make good instructional decisions and to be able to explain to others the foundation of that decision-making using evidence from both exemplary practice and research. One area of significance to the curriculum is that of vocabulary; the connection between vocabulary and reading comprehension as well as vocabulary and school performance in all content areas is one of the most strongly established in educational research (National Reading Panel, 2000).

Many researchers have presented strong evidence that multimedia have useful effects on language learning because of the authentic comprehensible input (Brett, 1995; Khalid, 2001). The effectiveness of multimedia technology like TV, computers, networks, video cassette recorders, and increasing access to such technologies aid the teaching procedure of unifying real-life situations with the target language (TL) into the language classroom, and many teachers have found more opportunities to use visual materials at all levels of foreign language teaching, and they have frequently used them effectively in language classes (Markham, 1999). The use of video and TV has grown rapidly due to the increasing focus on communicative aspects of language use (Cakir, 2006). However, language learners deal with some difficulties in understanding TV programs in target language. Therefore, mother tongue or target language captions are provided in order to enhance the learners' comprehension of a foreign language. Using captions - spoken information with visual context - to facilitate the comprehension of video materials is taken for granted by many educators and researchers since TV shows and programs seem to provide a very rich context for foreign language acquisition .

The dual-coding theory proposed by Paivio (1971) suggests that when pictures are added to the meaning, the number of signals connected with the message increases, so the viewers then will be more probable to keep the messages in mind. Many teachers recommend their students to watch TV and movies with captions in the belief that being exposed to the target language in this manner will increase their students' language proficiency level. It is also believed that whenever the captions are provided, the viewers are quite motivated to understand what is shown or said on television (Danan, 2004). The research on captioning shows that subtitle, i.e. the display of transcription of utterances of a video, improve the learners' performance on comprehension of a target language regardless of language background (Price, 1996; \& Markham 1989). The impact of captions on vocabulary learning was determined by Garza (1991), who found out that captions increased comprehension and memorization in advanced EFL learners. Subsequently, Baltova (1999) reported that captions had positive effects on vocabulary learning of inexperienced students. McCarthy (1990) claimed that no matter how well the student learns grammar, no matter how successfully the sounds of L2 (second language learners) are mastered, without words to express a wider range of meanings, communication in L2 just cannot happen in any meaningful way. Harley 
(1996) believed that vocabulary learning is a separable part of each student's life.

\subsection{Statement of the Problem}

In Iran, English is known as a foreign language so Iranian English language learners don't have opportunities to communicate outside the educational environment, i.e. schools and English institutes. Even in some educational systems and environments, the students are not provided by native-like situation; therefore, the learners may have more difficulties in comprehending and understanding the target language. Even if Iranian learners visit foreigners by chance, they may also have some problems in communicating with them in English. The curriculum in Iran is based on teaching grammar and reading comprehension but the sub-skill, such as vocabulary, is less emphasized; therefore, most students' oral communication skills are limited.

For Iranian students, who wish to study overseas, language is the main problem. Since they have studied in Iran for all their educational life, adjusting to a foreign environment is very difficult. Hence, almost all the students are suggested to pass English courses in institutes and be in native-like situations in order to develop their language knowledge and prepare themselves how to deal with difficulties while using a TL in native environment. It is evident that all the books taught in institutes include some audio parts with pictures but explaining concepts through movies scenes creates more realistic situations and provokes good discussions in the classrooms.

Any teachers who use a film with learners will have felt the thrill of excitement and the learners' anticipation of entertainment and enjoyment in the class (Danan, 2004). Movies are designed to appeal most directly and fully to our emotions and are entrenched in the learners' minds as a medium of entertainment and a means of learning. Koolstra and Beentjes (1999) define authentic materials such as movies, as appropriate and quality in terms of goal, objectives, learners' needs, and interest and natural in term of real life and meaningful communication. The art of cinema and its ability to attract people have always been an unbeatable power; therefore, encouraging English learners with this unique experience will enhance the learning and teaching processes.

\section{Review of Related Literature}

As the present study aims to look into the impact of watching captioned movies on the enhancement of vocabulary learning, it is of value to present the background of movie subtitles and captions and their application in teaching and learning. The story began when after the National Captioning Institute in the U.S. began transmitting closed-captioned TV programs (electronically imposed subtitles in the same language at the bottom of the TV screen) for the hearing impaired in 1980, a number of language teachers and researchers successfully experimented with the use of captioning for the teaching of ESL (English as a second language) or EFL (English as a foreign language) to hearing students. Researchers made their attempt to figure out whether captioned TV program can lead to improvement in language learning. They concluded that closed-captioning was a successful vehicle for improving L2 comprehension and acquisition (e.g. Price, 1983; Garza, 1991). Additionally, the students who were exposed to these multimedia programs showed grater interest in 
learning and held positive beliefs in terms of applying captions and subtitles .

The first attempt to empirically establish the relationship between captioned TV program and the learning of a foreign language was made by Price (1983) of Harvard University. He conducted a pilot project to investigate whether foreign students of ESL might benefit from captioned TV program in their study of language. Four-hundred and fifty students participated in the study, and the outcome indicated that captions significantly improved their overall comprehension of the linguistic information contained in the video material they were tested on.

In another study, Vanderplank (1988) made an attempt to look into the use of English language subtitles in BBC television programs. Fifteen university students of L2English at a high-intermediate and advanced level watched $\mathrm{BBC}$ television programs with English language subtitles in nine-hour-long sessions. Observation of these students as well as students' own retrospective reports about the use of subtitles and their performance on language-oriented activities revealed that they were able to follow text, sound, and picture simultaneously without resorting to reading only. Students were better able to understand "fast, authentic speech and unfamiliar accents" (p. 275), and they were really pleased in that they were armed with the ability to monitor how well they understood the spoken language against the text. Of particular interest in Vanderplank's finding is the point that the use of captions also helped the students achieve a high level of retention for the language used in the programs.

Similarly to Vanderplank, Gielen (1988) found that subtitled video enhanced the students' memory of the language used in the text of the subtitles. In his experiment, Dutch students of German were given an unannounced memory test after watching a video segment from a popular German show. One group watched it subtitled in Dutch, and another watched it without any subtitles. The test presented each original subtitle, accompanied by three distracters (i.e., a grammatically correct sentence which was syntactically different from the original subtitled sentence; a paraphrase of the original subtitle; and a sentence that had not appeared in the subtitles, but was still contextually possible). Findings revealed an overwhelming recall effect for subtitles (93\%) in the condition where people had watched the subtitled video. Learners who watched the video without any subtitles were able to recall only $43 \%$ of the utterances from the video that corresponded to the subtitles. It was suggested that subtitled videos can be helpful for retention of vocabularies.

Koskinen, Kane, Jensema, Markham and Knable (1995) analyzed the effects of captioned TV program on the incidental vocabulary acquisition of 72 volunteers who were inmates of Pennsylvania correctional facility. Subjects were randomly assigned to with/without captioned groups, watched nine science information segments over a period of nine weeks. Three post-tests consisting of word recognition, sentence anomaly, and word meaning measures were administered to evaluate the participants' acquisition of the targeted vocabulary. A questionnaire about viewing TV was also developed to assess the participants' perception of knowledge gained via the science videos and their opinion of the use of captioned TV program. The study did not indicate significant differences on the word recognition and sentence anomaly post-tests between the two groups, but the word meaning 
test resulted in significant differences favoring captioned TV program. The questionnaire data revealed that the participants had very positive response to the science videos and to the use of captioned TV program.

In the same fashion, Markham (1989) conducted an experiment with the participation of 76 university-level ESL students to determine the effects of captioned TV program on the comprehension of ESL university students. The results demonstrated substantial comprehension benefits for beginning, intermediate, and advanced ESL university students viewing captioned TV program. Garza (1991) also found substantial improvement in the comprehension of university-level ESL students and students learning Russian as a foreign language with captioned TV program.

Goldman (1993) concluded similarly that captioned TV program is a powerful motivator for teaching reading comprehension in intermediate and advanced ESL programs. Goldman (1996) also pointed that captioned TV program was a dynamic supplemental teaching aid if teachers could embellish it with various activities, e.g., previewing vocabulary (before viewing), building context (during viewing), predicting (during viewing) and discussion (after viewing).

To sum up, it seems that the above studies highlighted the significance of applying captioned TV programs on language learning skills, particularly vocabulary. As in a foreign language context the role of learning vocabularies is of significance for language learners in institutes, using captioned TV series can pave the way for the learners to improve their vocabulary learning.

\section{Research Questions}

The present study aims to answer the following questions:

Q1. Does watching captioned TV series have any effects on L2 learners' vocabulary development?

Q2. What are the learners' perceptions toward watching captioned TV series?

\section{Methodology}

\subsection{Participants}

After screening, participants of the current study were 40 intermediate-level English learners selected from a population of 96 EFL students studying English as a foreign language at Shokooh English institute in Nowshahr, Mazandaran, Iran. The sample was not ethnically diverse; in fact, all the participants were Iranians and their first language was Farsi. The participants, including just male students, ranged from 14 to 18 years of age who turned out to be at the same level of proficiency (intermediate) determined by Oxford Placement Test (OPT). Then, they were randomly divided into two groups i.e., experimental and control groups, each including 20 learners. The learners had studied 'True Color' series for almost two years at Shokooh Institute. These selected English language learners had no exposure to English speaking community, but a few of them had contact with native speakers of English. 


\subsection{Instrumentation}

The teaching material, beside the routine class activities and materials, was selected from a popular American TV series, 'Friends'. The suitability of the movies was confirmed through consultation with advisor and supervisor professor in proposal defense session. The other research tools were a pre-test and a semi-structured interview. OPT was applied to select the desirable intermediate participants to fit the purpose of the study. The pre-test was a 20-item vocabulary matching test, selected from another American TV series, 'How I met your mother?', included 20 words with twenty definitions based on proficiency level and students' background knowledge This test aimed to investigate the students' knowledge of vocabulary. The treatment involved the students in all groups watching the selected episodes once for twenty sessions during one semester. At the end of each class session, a part of each episode of the series was presented to the participants for about 15 minutes. The experimental group received episodes with English captions and the control group viewed the same episodes without captions. After the treatment, the participants took the post-test the same as the pre-test but with another TV series, i.e. 'Friends'.

\subsection{Procedures}

There was a combination of quantitative and qualitative procedures in this experiment. All the participants were males and after screening, they were randomly divided into two groups. OPT was taken to select intermediate-level participants. Then, the vocabulary matching test, as a pre-test was set before the treatment for specifying the participants' background vocabulary knowledge. The qualitative part of this study was done by conducting a semi-structured interview. One class was required to watch captioned episodes while the other one non-captioned episodes. The participants in the treatment group with captions were allowed to write down new words and expressions during viewing the series whereas the control group received no captions and they just watched the series. Each episode was presented to the students for 15 minutes in every session. After twenty sessions, a post-test was carried out to determine how learners develop their knowledge of vocabulary as a result of watching captioned and non-captioned TV series.

\subsection{Data Analysis}

Both paired and independent t-test procedure were conducted to analyze the data in terms of the participants' vocabulary development in both groups. Paired t-test analyzed the performance of one group before and after the experiment and independent t-test analyses were performed to determine if any variables affected students' performance to a statistically significant extent. The quantitative data was calculated by the Statistical Package for Social Science (SPSS) tool. As to the interview, the main points in the interview sessions were explained and taken into account to probe the learners' perceptions about using captioned TV series and its effectiveness on the learners' knowledge of vocabulary.

\section{Results}

To see the general distribution of the data and average scores, descriptive statistics were conducted on SPSS. Descriptive statistics indices such as mean, and standard deviation (SD), measuring the degree to which statistical data varies from the mean, were calculated to 
analyze data common characteristics. Mean difference for both experimental and control group from vocabulary matching pre- and post-test is illustrated in Figure 1. As the Figure shows, the highest mean value lies in the post-test of the experimental group (Mean of experimental group $=14.65$, Mean of control group $=13.35$ )

Graph 1. Mean difference for both groups on the pre- and post-test

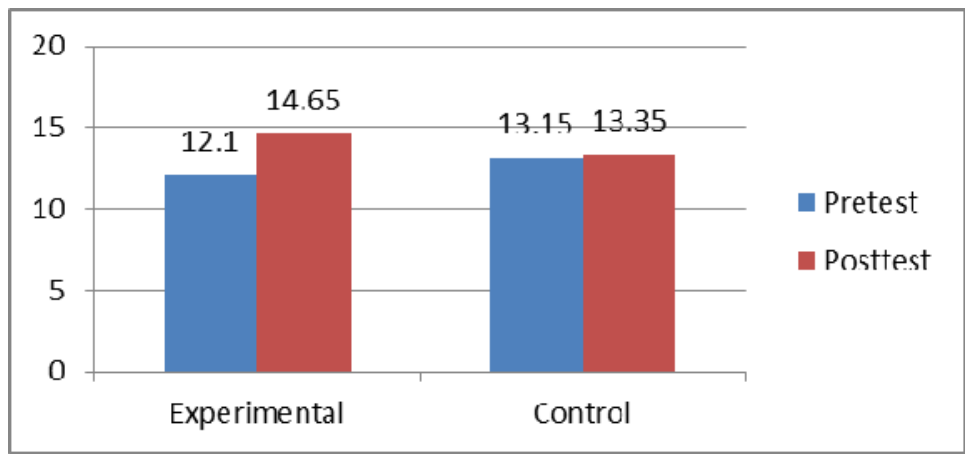

Paired-sample t-test, known as matched t-test or pairs t-test, was conducted to compare two sets of scores obtained from the same group along with answering to the first research question i.e., whether watching captioned TV series has any effects on L2 learners' vocabulary development. The results from paired test are summarized in Tables 1 and 2 . According to the mean scores of experimental group before and after treatment i.e. pre- and post-test, viewing English TV series with captions will improve the vocabulary knowledge of foreign language learners $(\mathrm{M}=14.65)$. The mean and standard deviation (SD) of experimental pre- and post-test are summarized in Table 1.

Table 1. Paired samples statistics of the experimental group

\begin{tabular}{|cc|c|c|c|c|}
\hline & & Mean & $\mathrm{N}$ & Std. Deviation & $\begin{array}{c}\text { Std. Error } \\
\text { Mean }\end{array}$ \\
\hline Pair 1 & ExpPretest & 12.1000 & 20 & 3.75430 & .83949 \\
\cline { 2 - 6 } & Expposttest & 14.6500 & 20 & 2.41214 & .53937 \\
\hline
\end{tabular}

The significance of difference observed within the means of experimental group through the application of paired t-test to the scores learners obtained from two vocabulary tests was 0.00 $(\mathrm{Sig}=0.00)$. This substantiated the fact that there was a statistically significant correlation within groups confirming the effect of captioned TV series on the EFL learners' vocabulary learning (see Table 2).

Table 2. Paired samples correlations of the experimental group

\begin{tabular}{|ll|c|c|c|}
\hline & & & \\
\hline Pair 1 & ExpPretest \& Expposttest & 20 & .853 & .000 \\
\hline
\end{tabular}

The independent t-test was run to compare the mean scores of the both groups on the 
post-tests. As shown in Table 3, significant difference or the probability figure- marked as 'Sig'- is smaller than 0.05 (it is 0.00 ), the difference can be true. In other words, the difference between the impacts of authentic materials with English caption and without caption was significant. On average, experimental group had improved significantly at a higher level than control group in target vocabulary learning. The descriptive statistics of the participants' performance in different groups on post-test are presented in Table 3 as well.

Table 3. Independent samples t-test for the experimental and control group

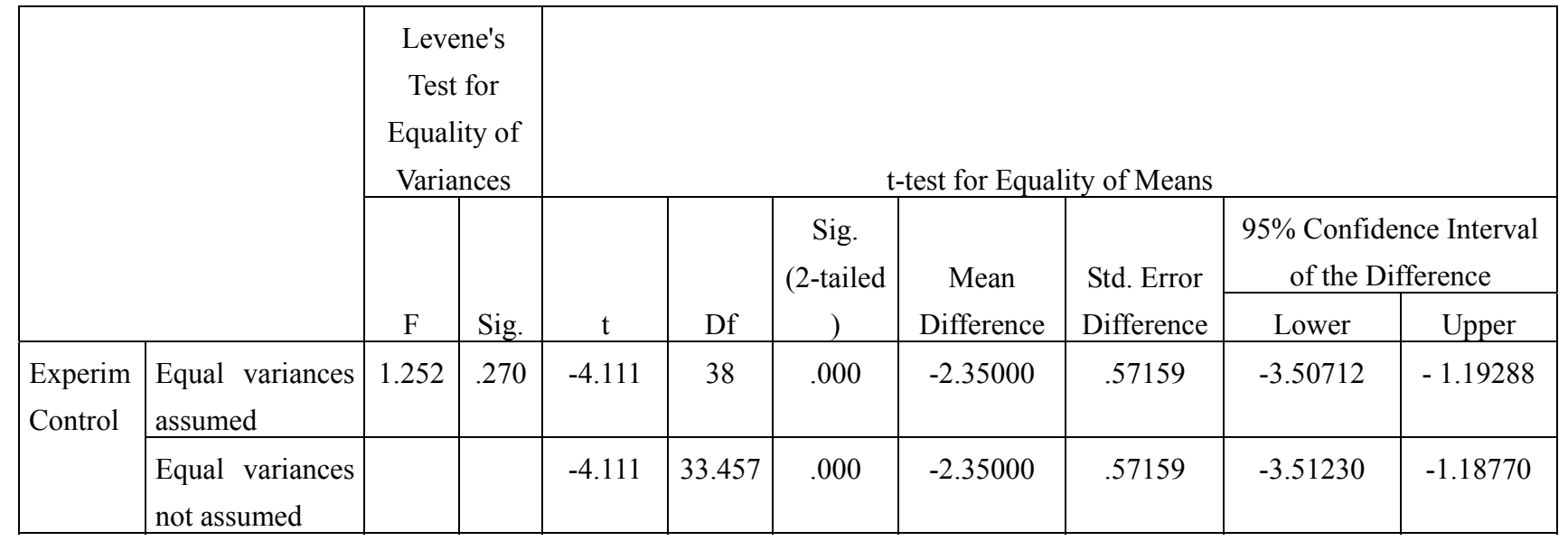

*The mean difference is significant at the 0.05 level.

\subsection{Results from Semi-Structured Interview}

The answer to the second research question was obtained by conducting a semi-structured interview regarding students' perception and preferences toward watching captioned TV series. The interview included twelve questions about listening comprehension skill, target vocabulary learning styles, the multimedia and caption technology. The students were allowed to elaborate on the answer of each question. Although some of them were lower than their proficiency level, the answers were quite significant and comprehensive. Most of the students in both groups indicated that listening comprehension is one of the most important skills and listening to English videos is vital for language learners and is a helpful means for knowing the words. They figured out that watching too mush English movies, listening to English songs, documentary and TV series regularly would improve their listening comprehension along with speaking skill and word knowledge and pointed that audiovisual media are closer to real-life because visual clues and context make it possible to view the message as much as listen to it. All the twenty students in the treatment group were quite familiar with captioning, but their perspectives were different. Most of them had positive view regarding captioning. They believed that watching captioned videos helps the students with word recognition and acquisition than traditional television watching or reading while listening.

\section{Discussion}

English movies and series help the learners to enrich their vocabulary knowledge due to they are really a series of dialogues set in different situations. Even a short part of a film 
encourages and helps the learners improve their vocabulary a great deal (Zarei, 2008; Zhang $\& \mathrm{Wu}, 2011)$. Authentic materials such as series engage the language learners in activities; thereby reduce anxiety and affective filter which allow the acquisition to take place (Hayati \& Mohammadi, 2009). The present study elaborated on the effectiveness of watching series with captions on Iranian EFL learners' vocabulary knowledge. Choosing the samples from intermediate male students in an institute in Nowshahr, they were given a vocabulary matching test to evaluate their English word knowledge as a pre-test. The scores taken from the test helped in realizing that there was quite no significance difference between the proficiency levels of the all participants.

According to the statistical results and findings from interviews, it can be justified that the participants believed that human beings are able to recall $10 \%$ of what they hear, $10 \%$ of what they visually perceive, and $80 \%$ of what they visually perceive and interact with. During watching captioned videos, students are not only watching and listening to the audio-visual material, but also interacting with it as they read the target text. This interaction of students with the text makes them try more to understand aural input and they pay more attention to captions. This attention leads to more focus on the spelling of the words, displayed on the screen which in return causes more retention of the new words from. If the language learners are familiar with the audio, they are able to match what they hear with what they see on the screen with more ease.

To sum up, the mean scores of participants in both groups have increased from pre- to post-test that means all students had a better performance. In other words, watching English series with captions has a positive effect on new vocabulary learning and most studies support captioning as an aid to learners' comprehension (e.g. Neuman, 1990; Jones 2004; Hayati \& Mohammadi, 2011). Some other research results have indicated that captioning can be a hindrance or distracting (e.g. Stweart \& Pertusa, 2004; Vandergrift, 2004). Besides, both Vandergrift and Yanagawa and Green (2008) pointed out that the use of written text might also delay learners' advancement of their listening ability, rendering them and make them unable to comprehend the second language in real-life situations where captions are not readily available.

\section{Conclusion}

The main purpose of the present research was to examine whether English series with and without captions could improve Iranian intermediate learners' vocabulary learning. After screening, the learners were divided into two groups. Before the experiment, a semi-structured interview and a pre-test were carried out and the scores were quite low. The experimental group received captions, while the control group viewed non-captioned episodes. After twenty sessions of treatment, the students were given a post-test. Although the scores were low, the result from t-tests revealed that those in experimental group showed better improvement in vocabulary learning than the control group.

There were several findings and perspectives from the interview results. The students in experimental group, with full English captions, indicated that providing them with English captions was so beneficial. Moreover, most of them stated that showing captions didn't 
distract them or interfere with their listening to the learning materials and reading the captions. They declared that writing down the new words in their notebooks helped them for further recall and encouraged them to find the meaning of the new words at home.

The focus of the study was on the development of some specific vocabulary items after watching some target language series episodes with and without captions. As stated earlier, the result from the present study indicates that using captioned videos as an English teaching material in multimedia classrooms can assist learners to receive the language through multisensory channels and help them to develop their vocabulary learning process.

\section{References}

Abdolmajid Hayati, A., \& Mohmedi, F. (2011). The effect of films with and without subtitles on listening comprehension of EFL learners. British Journal of Educational Technology, 42(1), 181-192. http://dx.doi.org/10.1111/j.1467-8535.2009.01004.x

Baltova, I. (1999). Multisensory language teaching in a multidimensional curriculum: The use of authentic bimodal video in core French. Canadian Modern Language, 56, 31-48. http://dx.doi.org/10.3138/cmlr.56.1.31

Brett, P. (1995). Multimedia for listening comprehension: The design of a multimedia-based resources for developing listening skills. System, 23, 1-10. http://dx.doi.org/10.1016/0346-251X(94)00054-A

Cakir, (2006). Integrated Vocabulary Instruction. Learning Point Associates, 7-10.

Center for Applied Linguistics. (1989). Evaluating the benefits of closed-captioned TV programming as instructional material for ESL students. Washington, D C: Author.

Danan, M. (2004). Captioning and subtitling: Undervalued language learning strategies. Meta, 49, 67-77.

Garza, T. (1991). Reading television. Educational Leadership, 39, 296-310.

Gielen, M. (1988). Perceptie en ondertitels: De parafoveale en perifere informatieverwerking van ondertitel. Unpublished manuscript, University of Leuven.

Goldman, M. (1993). Using captioned TV for teaching reading. Fastback, 359, PHI DELTA KAPPA Educational Foundation.

Harley, B. (1996). Introduction: Vocabulary learning and teaching in a second language. The Canadian Modern Language Review, 53(1), 3-11.

Khalid, A. (2001). The effect of multimedia annotation modes on L2 vocabulary acquisition: A comparative study. Language Learning \& Technology, 5(1), 202-232.

Koolstra, C., \& Beentjes, W. (1999). Children's vocabulary acquisition in foreign language through watching subtitled television at home. Educational Technology Research and Development, 47(1), 51-60. 
Koskinen, P. S., Knable, J. E, \& Jensema, C., J. \& Markham, P. L., \& Kane, K.W. (1995). Captioned television and the vocabulary acquisition of adult second language correctional facility residents. Journal of Educational Technology Systems, 24(4), 359-373.

Krashen, S. (1985). The Input Hypothesis: Issue and implications. New York: Longman.

Markham, P. (1989). The effects of captioned television videotapes on the listening comprehension of beginning, intermediate, and advanced ESL students. Educational Technology, 29(10), 38-41.

Markham, P. (1999), Captioned videotapes and second-language listening word recognition. Foreign Language Annals, 321-328. http://dx.doi.org/10.1111/j.1944-9720.1999.tb01344.x

McCarthy, M. J. (1990). Vocabulary. Oxford, UK: Oxford University Press: Cambridge.

Neuman, S., \& Koskinen, P. (1992). Captioned television as comprehensible input: effects of incidental word learning in context for language minority students. Reading Research Quarterly, 27, 95-106.

Paivio, A. (1971). Imagery and deep structure in the recall of English nominalization. Journal of Verbal Learning and Verbal Behavior, 10, 1-12.

Price, K. (1983). Closed-captioned TV: An untapped resource. MATSOL Newsletter. 12(2), 4-5.

Rees, T. (1993). Closed- captions in the classroom. Unpublished manuscript. Northampton, MA: International Language Institute of Massachusetts.

Smith, J. (1990). Closed-captioned television and adult students of English as a second language. Arlington, VA: Arlington Refugee Education and Employment Program. ERIC Clearinghouse. ED 339250.

Stewart, M. A., \& I. Pertusa, 2004. Gains to language learners from viewing target language closed-captioned films. International Journal of Asian Social Science, 37(3), 438-447. http://dx.doi.org/10.1111/j.1944-9720.2004.tb02701.x

Vanderplank, R. (1988). The value of teletext subtitles in language learning. ELT Journal, 42, 272-281. http://dx.doi.org/10.1093/elt/42.4.272

Zarei (2008). The effects of bimodal, standard and reversed subtitling on L2 vocabulary recognition and recall. SID journal, 5, 65-84.

Zhang, Y., \& Wu, L. (2011). A HYBRID TS-PSO optimization algorithm. Journal of Convergence Information Technology, 6(5), 169-174. 


Macrothink
Instrtute

\section{Copyright Disclaimer}

Copyright for this article is retained by the author(s), with first publication rights granted to the journal.

This is an open-access article distributed under the terms and conditions of the Creative Commons Attribution license (http://creativecommons.org/licenses/by/3.0/). 